\title{
Em memória da professora Rachel Joffily Abath: Origens, vida acadêmica, saudades e imagens
}

\author{
Luciana Ferreira da Costa \\ Alan Curcino Pedreira da Silva \\ André Joffily Abath \\ Maria do Céo Costa de Oliveira
}

COMMUNICATIONS

\begin{abstract}
Resumo
Diante da trajetória de vida da professora Rachel Joffily Abath, este texto rememora, como síntese em homenagem póstuma após cinco anos de seu falecimento, a sua história e, em especial, o seu legado à Biblioteconomia e Ciência da Informação no Brasil. Quatro perspectivas são contadas neste texto: as origens e constituição familiar da professora Rachel; a história de sua vida acadêmico-profissional, com maior contributo às atividades de ensino e pesquisa em instituições universitárias especificamente na Universidade Federal da Paraíba e no Centro Universitário de João Pessoa -; uma declaração da importância e saudade da professora; e imagens fotográficas.
\end{abstract}

Palavras - chave

Homenagem póstuma; História de vida; Biblioteconomia e Ciência da Informação - Brasil; Rachel Joffily Abath

\section{In memory of the professor Rachel Joffily Abath: Origins, academic life, longing and images}

\begin{abstract}
Given the life trajectory of Professor Rachel Joffily Abath, this text recalls, as synthesis memorial five years after her death, her story and, in particular, her legacy to the Library and Information Science in Brazil. Four perspectives are presented in this paper: the origins and composition of the family of Professor Rachel; the story of her professional academic life, with greater contribution to teaching and research universities - specifically The Federal University of Paraíba and The University Center of João Pessoa -; a statement of the importance and longing; and memories through photographs.
\end{abstract}

Keywords

Memorial, life story, Library and Information Science - Brazil; Rachel Joffily Abath

\section{Por uma homenagem póstuma}

Este texto tem como objetivo prestar uma homenagem póstuma à professora brasileira Rachel Joffily Abath, que dedicou sua vida à família e ao ensino e pesquisa em Biblioteconomia e Ciência da Informação, a completar 5 anos de seu falecimento em 23 de março deste ano de 2012.

Como uma bricolagem historiográfica, servindo-se de depoimentos e da documentação do currículo da professora Rachel Joffily Abath, o texto apresentado é composto por quatro partes.

A primeira parte trata das origens de professora Rachel, nas palavras escritas por seu único filho, André Joffily Abath. É contada aqui uma síntese da história de sua vida na perspectiva familiar. Uma perspectiva privilegiada. 
A segunda parte é dedicada à sua vida acadêmico-profissional, nas palavras escritas por Luciana Ferreira da Costa e Alan Curcino Pedreira da Silva. Luciana foi aluna de professora Rachel quando da realização do seu curso de Bacharelado em Biblioteconomia pela Universidade Federal da Paraíba, entre os anos de 1997 e 2002. Já Alan, este foi aluno de professora Rachel quando da realização do seu curso de Mestrado em Ciência da Informação, entre os anos de 2001 e 2003, e foi colaborador de professora Rachel como professor do curso de Bacharelado em Administração do Centro Universitário de João Pessoa ainda no ano de 2003, quando a mesma foi Coordenadora deste curso.

A terceira parte é uma declaração, nas palavras escritas por Maria do Céo Costa de Oliveira, sobre o quanto a professora Rachel foi importante e, no seu legado, deixou-nos ensinamentos e saudade. Maria do Céo foi orientadora do curso de Mestrado em Administração realizado pela professora Rachel, entre os anos de 1981 a 1985, e amiga desde então.

Por fim, como quarta parte deste texto, fotografias de fases da história de vida de professora Rachel são apresentadas. Recordação por imagens escolhidas por seu filho André.

Como modus operandi, pela pessoalidade e implicação dos autores, a condução da escrita deste texto a partir deste momento se apresenta, nos depoimentos narrados, ora na $1^{\text {a }}$ pessoa do singular ou do plural.

Através da leitura deste texto, convidamos a todos a rememorar conosco a história da pessoa da professora Rachel. Seu contributo à Biblioteconomia e Ciência da Informação no Brasil é um legado para quem a conheceu, pautado em uma sólida formação e nobre construção familiar e de laços de amizade. Por tudo isso, os autores, organizadores deste texto, sentem-se honrados e orgulhosos em realizar esta merecida homenagem póstuma.

Como diz a estrofe da velha marchinha de carnaval brasileiro: "recordar é viver, essa noite eu sonhei com você!"

\section{Origens}

Minha mãe nasceu Rachel Tavares Joffily Bezerra, em João Pessoa, no dia 9 de novembro de 1940, filha de Guilherme Joffily Bezerra de Mello e Aglaé Tavares Joffily Bezerra. Ainda na infância, morou em Campina Grande (cidade mais próxima da origem dos Joffily) e em Salvador, onde estudou em colégio interno.

Em 1957, a família - minha mãe, seus pais, e os irmãos (ela teve quatro irmãos, Irenêo, Antônio Guilherme, Ruth e Marcelo) - mudam-se para Roma, e lá ficam por mais de um ano. Meu avô Guilherme era médico, e trabalhava para o Instituto Nacional de Imigração e Colonização. Daí as diversas mudanças. Nesse período, minha mãe aprende italiano e inglês, uma vez que estudava em um colégio americano. Quando voltam ao Brasil, estabelecem-se no Rio de Janeiro, no bairro de Copacabana - onde minha avó morou até falecer no ano de 2011, e ainda mora a minha tia Ruth.

Em 1959, minha mãe finaliza seus estudos colegiais, no Sacré-Coeur de Marie, também em Copacabana. Lá aprende o francês, que iria depois aperfeiçoar morando em Paris, e que falou perfeitamente até o fim da vida. Entre 1961 e 1964, ela faz sua graduação em Biblioteconomia pela Biblioteca Nacional e Universidade Federal do Estado do Rio de Janeiro, no Brasil.

Logo depois, toma uma decisão radical: passar um ano em Paris, aperfeiçoando o francês, e trabalhando como babá. Vai em 1965.

Quanto retorna ao Brasil, trabalha no Serviço Federal de Processamento de Dados, e ajuda a fundar sua biblioteca sobre esse período, minha mãe sempre contava com orgulho ter visto a passeata dos cem mil contra a ditadura.

Meu pai, Hugo Montenegro Abath, e minha mãe eram primos em terceiro grau, e as famílias próximas desde os anos 1930, em João Pessoa. Em 1973, meu pai visita o Rio de janeiro. Minha mãe o guia pela cidade. Apaixonamse e casam 4 meses depois, em 18 de dezembro de 1973.

Mudam para João Pessoa - minha mãe estava fora da cidade desde os anos 1940. Lá, meu pai já era professor de Medicina na Universidade Federal da Paraíba, e responsável pelo Laboratório de Radioisótopos do Centro de Saúde. 
Poucos anos depois, seguem para Londres, onde meu pai faria Mestrado em Medicina Nuclear no Guy's Hospital.

Então, eu, André, nasço ainda em Londres, em 14 de julho de 1977.

Voltamos ao Brasil em 1979.

A vida profissional dela a partir daqui é dedicada a uma das grandes paixões da sua vida, a Biblioteconomia e Ciência da Informação. Este capítulo se refere à sua vida acadêmica.

Neste caminho, meu pai falece em 1991, em casa, e minha mãe, em 23 de março de 2007, no bairro da Gávea, no Rio de Janeiro.

\section{Vida acadêmica}

Nossa professora Rachel Joffily Abath foi uma importante decana da Biblioteconomia e Ciência da Informação no Brasil que viveu intensamente a academia.

Como dito por seu filho André, professora Rachel se graduou em Biblioteconomia pelo antigo curso da Biblioteca Nacional e da Universidade Federal do Estado do Rio de Janeiro. Mais tarde, realizou Mestrado em Administração pela Universidade Federal da Paraíba e PhD. em Políticas Sociais pela University of Manchester, Inglaterra.

Comunicativa e articulada, falava com fluência quatro idiomas além do português: francês, espanhol, italiano e inglês.

No início da sua carreira trabalhou no Serviço Federal de Processamento de Dados, mas fez do ensino e da pesquisa a sua profissão, que exerceu com grande paixão ao longo de sua vida.

Duas foram as instituições de ensino superior nas quais professora Rachel trabalhou: a Universidade Federal da Paraíba; e o Centro Universitário de João Pessoa - mais conhecido pelo seu acrônimo UNIPÊ. Da Universidade Federal da Paraíba foi professora durante 24 anos, entre os anos de 1979 e 2003, até quando se aposentou nesta instituição e, ainda com uma energia e vitalidade motivadora, ingressou como professora do UNIPÊ no ano de 2003, aposentando-se definitivamente em 2004.

Sempre trabalhou com a informação e sua gestão relacionada à cidadania e ao desenvolvimento, realizando pesquisas em organizações não-governamentais e Centros de Documentação e Comunicação Popular. Defendia um conceito de informação inovador para a sua época, mesmo antes de se falar em Ciência da Informação no Brasil. Defendia a informação como instrumento transformador da sociedade que não necessariamente estaria atrelado a um suporte. Entendia que nem sempre a informação estaria registrada, mas seria objeto também de seus estudos.

Desenvolveu pesquisas com publicações nacionais e internacionais sobre a utilização da informação e das tecnologias da informação e comunicação por organizações não-governamentais, enfatizando, até o fim da sua vida a questão do gênero feminino e seu processo de empoderamento social através da informação. Mesmo sua tese de doutoramento foi sobre tal temática, aprovada com distinção e louvor (ABATH, 2000).

Durante a década de 1990, em trabalho coletivo com o antigo Departamento de Biblioteconomia e Documentação da Universidade Federal da Paraíba, contribuiu para ações de pesquisa e extensão sobre informação para cidadania e desenvolvimento, como as praticadas junto à Casa Pequeno Davi, uma organização que tem como objetivo contribuir para a promoção dos direitos da criança e adolescente em situação de risco social, através de ações de educação integral e de intervenção nos espaços políticos da Paraiba (CPD, 2012).

Só mais adiante, dedicou-se aos estudos e produção sobre a informação, comunicação popular e educação relacionadas ao gênero feminino, tendo como importantes parceiros os professores Duncan Scott, seu antigo orientador de PhD. e professor da University of Manchester, e Timothy Denis Ireland, professor da Universidade Federal da Paraíba e da Organização das Nações Unidas para a Educação, Ciência e Cultura.

$\mathrm{Na}$ graduação, esteve vinculada ao ensino nos cursos de Biblioteconomia da Universidade Federal da Paraíba e Administração do UNIPÊ. Na pós-graduação, lecionou em cursos de especialização e, em nível de mestrado, lecionou nos cursos de Biblioteconomia, e posteriormente Ciência da Informação, além de Administração, todos pela Universidade Federal da Paraíba. 
Dedicou-se, da graduação à pós-graduação, ao ensino de disciplinas como: Planejamento Bibliotecário; Organização e Administração de Bibliotecas; Informação e Sociedade; e Administração de Sistemas de Informação.

Professora Rachel foi coordenadora do $1^{\circ}$ curso de Mestrado em Biblioteconomia das Regiões Norte e Nordeste do Brasil, entre os anos de 1987 a 1993, da Universidade Federal da Paraíba. Nessa época, sob sua coordenação este curso chegou ao seu maior conceito, classificado como B+ pela Coordenação de Aperfeiçoamento de Pessoal de Nível Superior, organismo vinculado ao Ministério de Educação do Governo do Brasil.

O curso de Mestrado em Biblioteconomia, pela sua história, originou o curso de Mestrado em Ciência da Informação desta mesma universidade, do qual professora Rachel também foi coordenadora entre os anos de 2000 a 2003 , bem como originou o atual Programa de Pós-Graduação em Ciência da Informação também desta universidade (UFPB, 2012).

Se quando coordenadora do curso de Mestrado em Biblioteconomia este chegou ao seu maior conceito, diferentemente quando coordenadora do curso de Mestrado em Ciência da Informação este recebeu seu menor conceito, nota 2. Uma fase que testificou o quanto guerreira e corajosa em enfrentar desafios a professora Rachel foi, apesar de o momento coincidir com a proximidade de sua aposentadoria junto à Universidade Federal da Paraíba.

Em entrevista, perguntada sobre esse período desafiador do curso de Mestrado em Ciência da Informação, ressaltou a professora Francisca Arruda Ramalho, colega de trabalho, companheira de viagens e amiga de professora Rachel:

\begin{abstract}
Essa pergunta se constitui, para mim, em muitas interrogações sem respostas. Momentos mais críticos, nós já havíamos passado. O Departamento estava investindo na qualificação de doutores para minimizar a dependência de professores de outros departamentos. Esse era um ponto nevrálgico. As causas? Prefiro dizer que se constituiu na morte de muitos sonhos, tanto da parte do corpo docente quanto discente. [...] Arregaçamos as mangas, os colegas e eu, e o Departamento começou com novas investidas, principalmente, na qualificação e contratação de doutores, visando um futuro promissor (COSTA et al, 2009, p. 151).
\end{abstract}

Outro fator importante na trajetória de professora Rachel foi o momento em que liderou a idealização e publicação de hoje um dos mais importantes e respeitados periódicos da área de Ciência da Informação no Brasil com repercussão internacional, o periódico Informação \& Sociedade: Estudos, que no ano de 2011 completou 20 anos de existência (I\&S, 2012; FREIRE \& FREIRE, 2011).

Ainda em entrevista com a professora Francisca Arruda Ramalho, perguntada sobre a importância deste periódico, esta ressaltou:

Como qualquer periódico científico, a publicação do primeiro número de Informação \& Sociedade: Estudos, em 1991, foi um marco para a comunidade acadêmica que o cria, no caso, o Curso de Mestrado em Biblioteconomia [CMB]. Também diria que foi uma iniciativa louvável e corajosa dos que faziam o $\mathrm{CMB}$, liderada pela coordenadora do $\mathrm{CMB}$, na época, professora Rachel Joffily Abath, que não media esforços em seus intentos. Deduzimos, do que afirmou o seu Conselho Editorial na época, que o referido periódico já surgiu rumando para sua consolidação (COSTA et al, 2009, p. 150).

Professora Rachel ainda foi orientadora de trabalhos de conclusão de cursos de graduação e de mestrado, participou de diversas bancas para seleção/concurso ao magistério de ensino superior e realizou diversas conferências e palestras no Brasil e exterior. Sua atuação como professora foi exemplar.

Com espírito associativo, por vezes bastante provocativo, mas sempre bem humorado, professora Rachel deixa a herança da educação não apenas ao seu filho André, contudo às centenas de pessoas que tiveram também a experiência privilegiada de serem seus alunos. 
Assim, a contribuição da Professora Rachel Joffily Abath para a área da Biblioteconomia e Ciência da Informação é inegável.

\section{Saudades}

Rachel foi uma grande mulher em todos os sentidos. Sua personalidade deixou fortes impressões em todos com quem conviveu.

Ainda me lembro do primeiro encontro com Rachel, no Campus de João Pessoa da Universidade Federal da Paraíba. Foi tão marcante como todos os demais contatos que fizemos. Ainda hoje esta cena mantém-se muito viva na minha memória. Era manhã e eu, recém-chegada do meu doutorado, estava no meu ambiente de estudos, quando, timidamente, mas sorridente, da porta ela perguntou se eu era Maria do Céo. Respondi-Ihe que sim. Então, Rachel convidou-me para orientar sua dissertação de mestrado, no Curso de Pós-Graduação em Administração.

Aquele seria meu primeiro trabalho como orientadora neste nível de estudos. A partir daí, nossos encontros se amiudaram; nossa amizade e, sobretudo, a confiança mútua aumentaram. O trabalho científico foi concluído, defendido e aprovado com nota máxima, distinção e louvor, como tudo o que Rachel fez em vida.

Costumávamos nos falar, pelo menos, três vezes todos os dias. Ainda ouço o som da sua voz, meio carioca, meio nordestina. Ela sempre começava entusiasmadamente: "Céo!" Rachel tinha uma conversa muito inteligente e divertida. Sempre que eu queria saber algo sobre diferentes fatos, era dela que me lembrava para consultar, perguntar, esclarecer, porque a resposta era atual, rápida e fundamentada.

Logo quando soube de sua doença, que mais tarde a levou de nós, fui visitá-la algumas vezes, e ela era uma fortaleza. Parecia não estar tão doente, sempre a rir e a falar. No hospital, poucos dias antes de nos deixar, sorrindo (ela nunca perdeu seu sorriso), perguntou-me por meu netinho, Giuseppe, que ela sabia que era a grande alegria de minha vida.

No momento em que soube de sua partida, fiquei com uma tristeza imensa; havia perdido meu oráculo, minha conselheira, a amiga em quem eu tanto confiava. Passei a dizer a várias pessoas: "Eu quero encontrar outra Rachel, com quem eu não tenha o menor constrangimento de suspender uma conversa telefônica." Tamanha era nossa confiança. Ainda não encontrei ninguém igual.

Permaneci muito tempo com ímpetos de ir ao telefone para falar com ela, porém a realidade me parava no caminho. E eu dizia: "Se Rachel estivesse viva, eu tiraria esta dúvida." Sua voz, seu semblante, seu sorriso marcante ainda vivem em mim...

O papel de mãe foi também muito importante na vida de Rachel. André, seu único filho, hoje homem realizado, era seu tudo. Mas ela o criou para ser independente, de atitudes sensatas. Ele é, sem dúvida, o legado desta inigualável mulher, sua continuação.

Rachel, você permanece viva no coração de todos nós, seus amigos.

\section{Saudades!}




\section{Imagens}

Rara vez a palavra e a imagem sobre determinado assunto se igualam no entendimento.

Quando isso acontece, você viu com o coração.

José Spinola

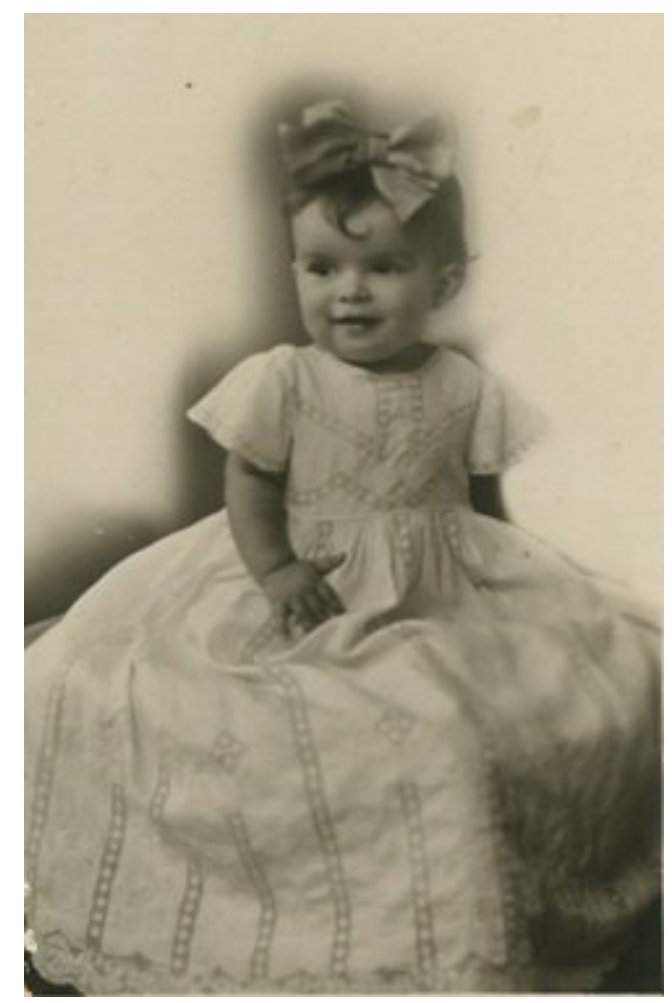

Foto 1 - Rachel com 6 meses, João Pessoa, Brasil

Fonte: acervo pessoal de André Joffily Abath

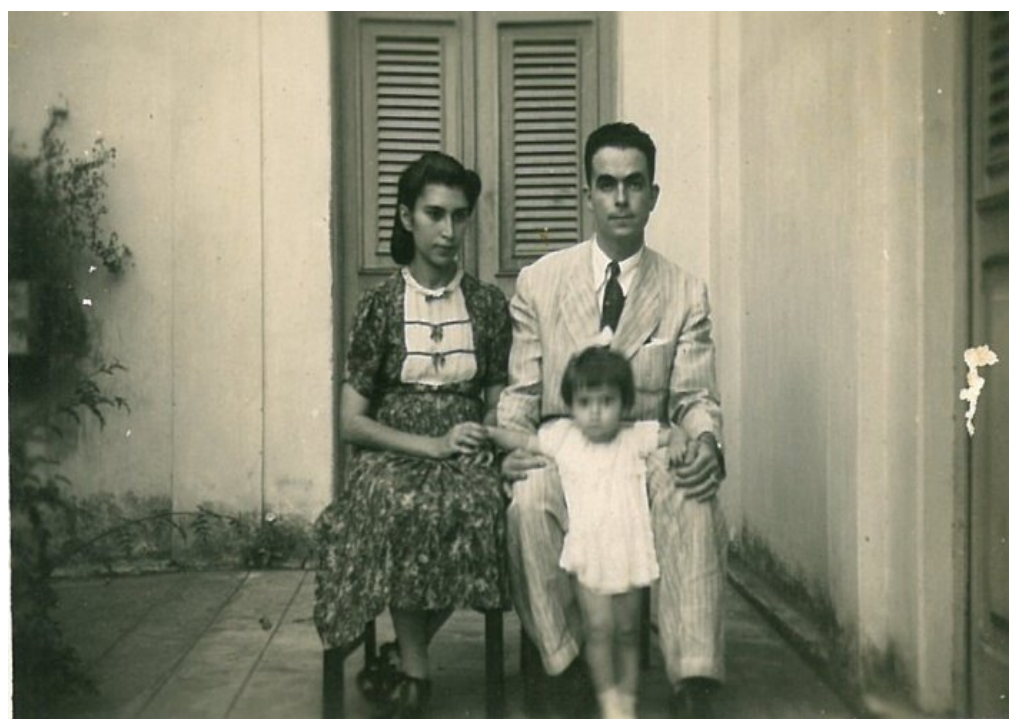

Foto 2 - Rachel com seus pais Guilherme e Aglaé, João Pessoa, Brasil

Fonte: acervo pessoal de André Joffily Abath 


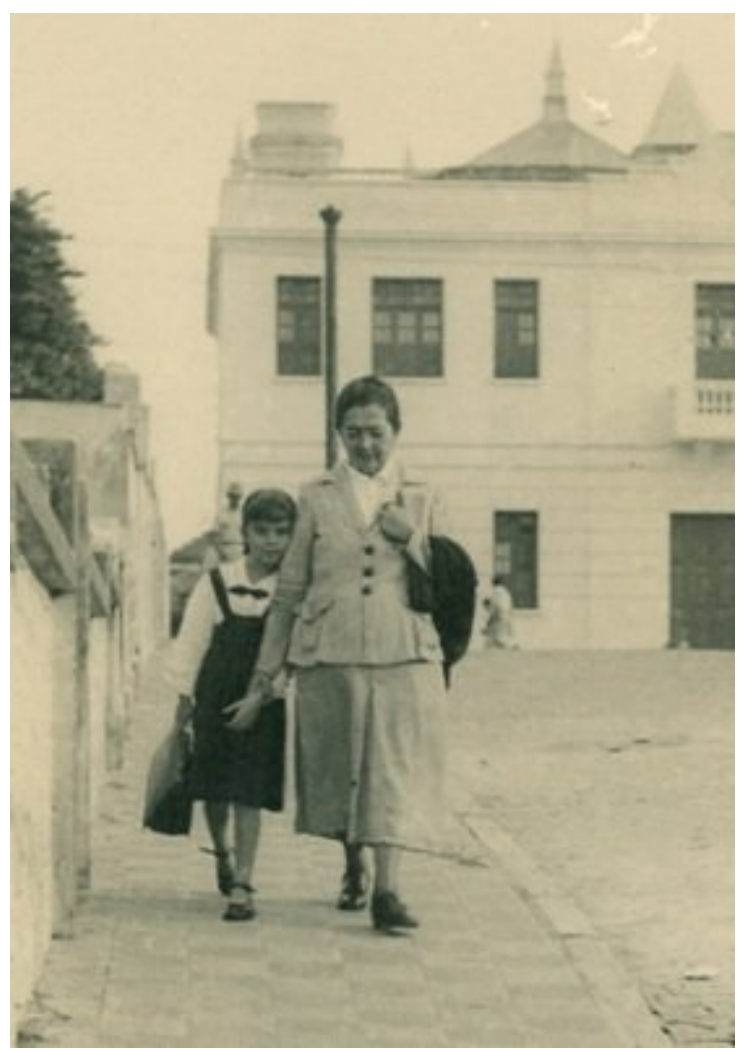

Foto 3 - Rachel com sua avó Marieta Joffily, Campina Grande, Brasil Fonte: acervo pessoal de André Joffily Abath

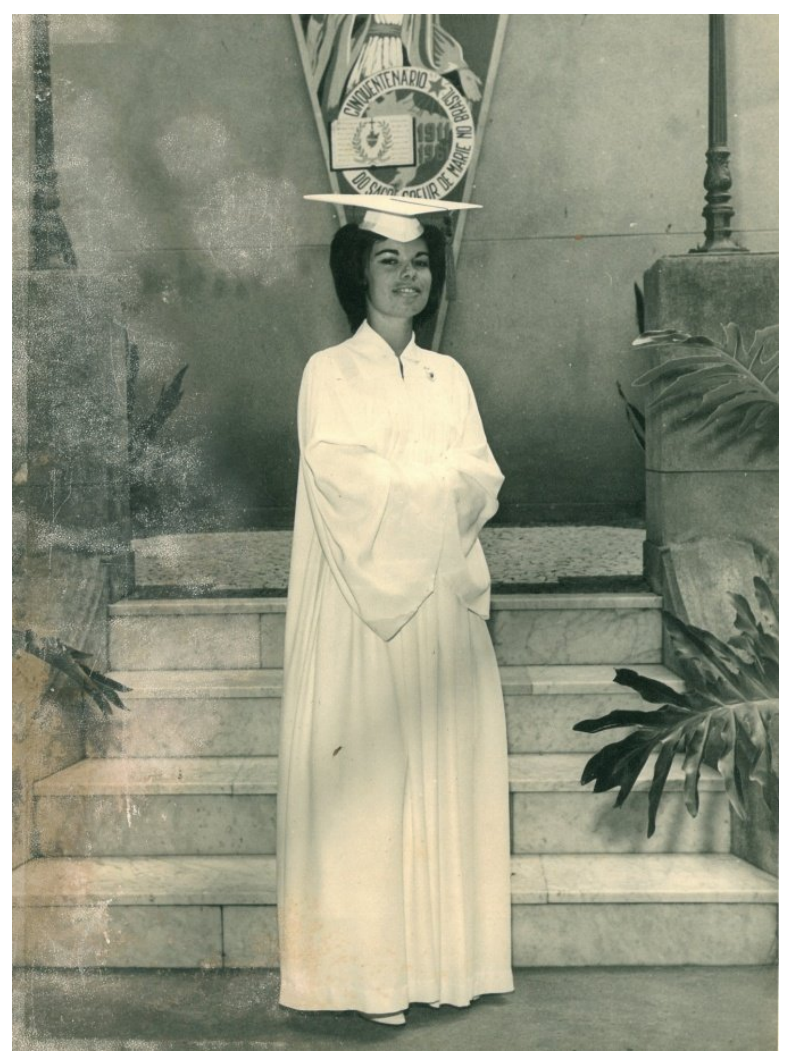

Foto 4 - Formatura de Rachel no Colégio Sacre-Coeur de Marie, Rio de Janeiro, Brasil Fonte: acervo pessoal de André Joffily Abath 


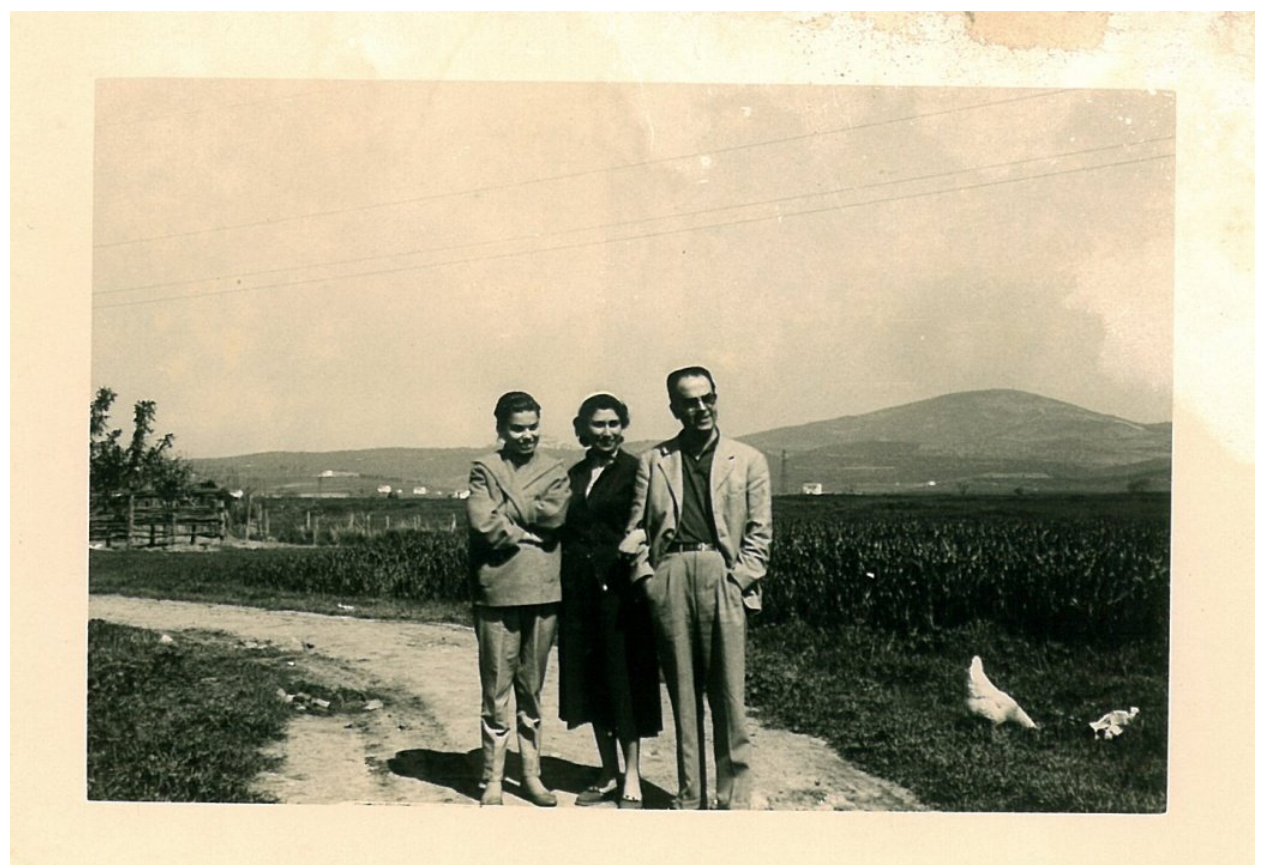

Foto 5 - Rachel com seus pais Guilherme e Aglaé, interior da Itália Fonte: acervo pessoal de André Joffily Abath

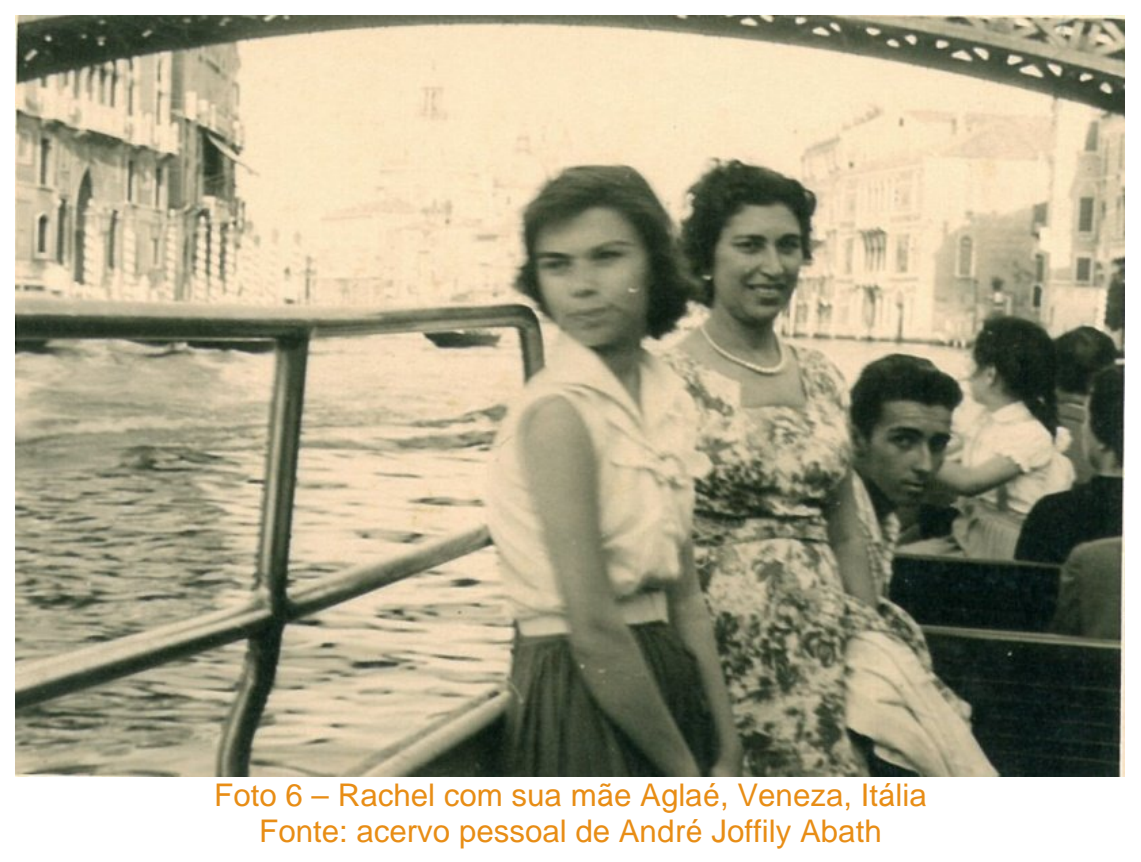




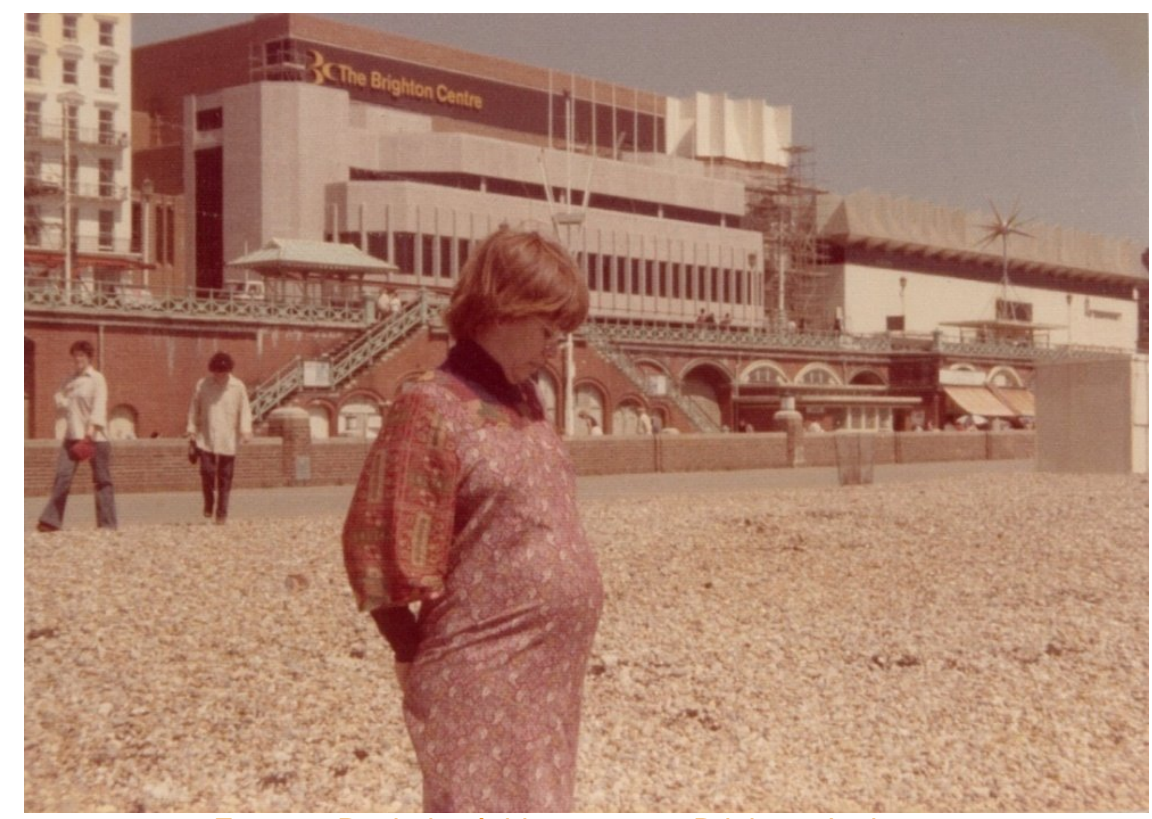

Foto 7 - Rachel grávida em 1976, Brighton, Inglaterra

Fonte: acervo pessoal de André Joffily Abath

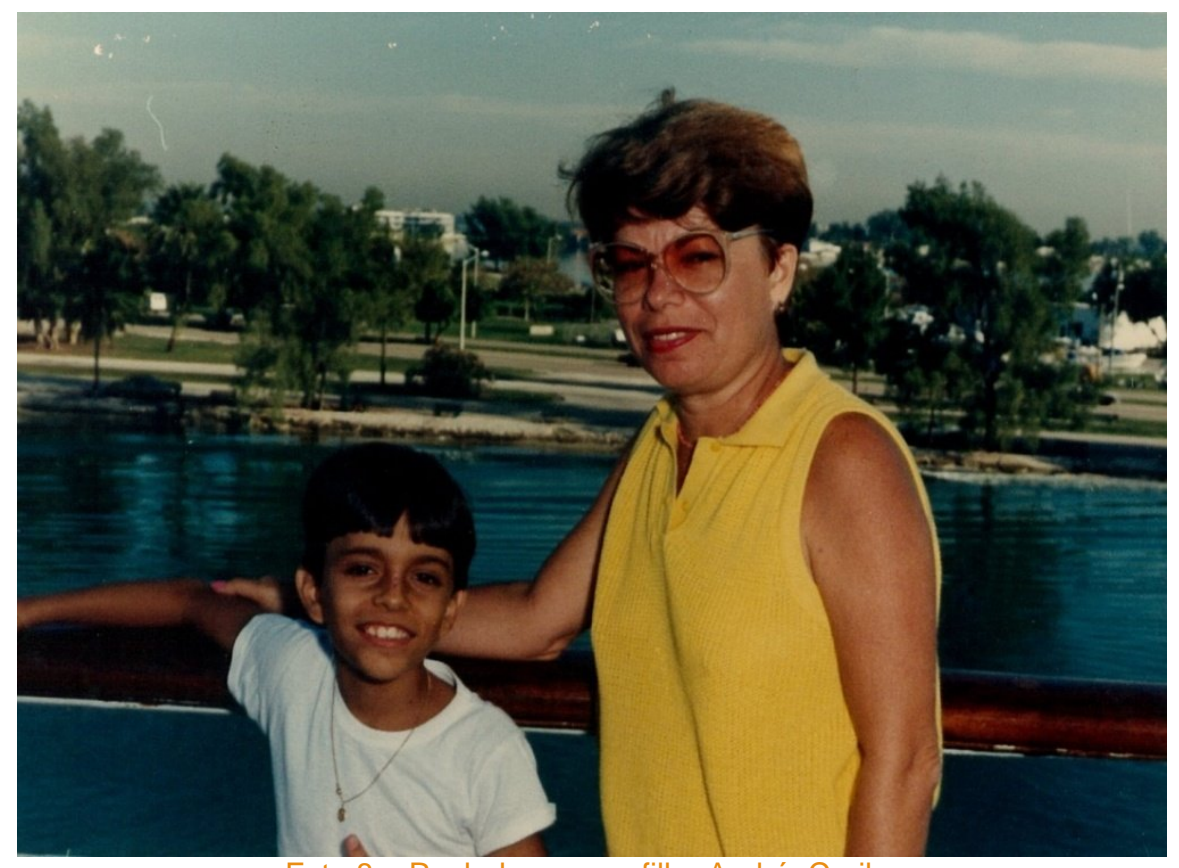

Foto 8 - Rachel com seu filho André, Caribe

Fonte: acervo pessoal de André Joffily Abath 


\section{Referências}

ABATH, Rachel Joffily. (2000). Women's empowerment: the contribution of women's groups in Carirys Northeast Brazil. Manchester: UM, 2000. Thesis (PhD. in Social Policy). The University of, United Kingdon, Department of Law and Applied Social Sciences.

CASA PEQUENO DAVI (CPD). (2012). Nossa missão. Disponível em: http://www.pequenodavi.org.br/v3/casa-pequeno-davi/nossamissao/. Aceso em: 11 de jan. 2012.

CONSELHO NACIONAL DE DESENVOLVIMENTO CIENTÍFICO E TECNOLÓGICO (CNPq). (2012). Currículo do Sistema de Currículo Lattes (Rachel Joffily Abath). Disponível em: http://lattes.cnpq.br/4266936917184781. Acesso em: 11 jan. 2012.

COSTA, Luciana Ferreira da et al. (2009). A Pós-Graduação em Ciência da Informação na UFPB: entrevista com a professora Francisca Arruda Ramalho. Inf. \& Soc.:Est., João Pessoa, v.19, n.3, p. 147-155, set./dez.

FREIRE, Gustavo \& FREIRE, Isa Maria.(2011). 20 anos de Informação \& Sociedade: Estudos (Editorial). Inf. \& Soc.:Est., João Pessoa, v.21, n.2, p. 9-10, maio/ago.

INFORMAÇÃO \& SOCIEDADE: ESTUDOS (I\&S). (2012). Disponível em: http://periodicos.ufpb.br/ojs2/index.php/ies. Acesso em: 11 jan. 2012.

UNIVERSIDADE FEDERAL DA PARAÍBA (UFPB). (2012). Programa de Pós-Graduação em Ciência da Informação. Ciência da Informação na UFPB. Disponível em: http://dci.ccsa.ufpb.br/ppgci/?seca0=1\&id=1. Acesso em: 11 jan. 2012. 
Biblios In memory of the professor Rachel Joffily Abath

\section{Dados dos autores}

Luciana Ferreira da Costa

Mestre em Ciência da Informação pela Universidade Federal da Paraíba, Brasil. Professora da Universidade Federal da Paraíba, Brasil.

lucianna.costa@yahoo.com.br

\section{Alan Curcino Pedreira da Silva}

Doutorando em Filosofia pela Universidade Federal da Paraíba. Professor da Universidade Federal de Alagoas, Brasil.

alancurcino@hotmail.com

André Joffily Abath

Doutor em Filosofia pela University of Sheffield, Inglaterra. Professor Universidade Federal de Minas Gerais, Brasil. andreabath@gmail.com

Maria do Céo Costa de Oliveira

Doutora em Administração pela University of Bath, Inglaterra. Professora do Centro Universitário de João Pessoa, Brasil.

mariaceo@unipe.br

Recibido - Received: 2011-05-09

Aceptado - Accepted: 2012-03-30

\section{(cc) EY-NC-ND}

This work is licensed under a Creative Commons

Attribution-Noncommercial-No Derivative Works 3.0 United States License.

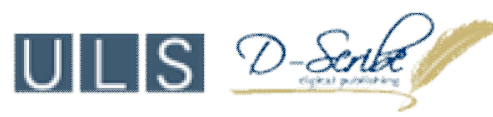

This journal is published by the University Library System of the University of Pittsburgh as part of its $\underline{D-S c r i b e}$ Digital Publishing Program and is cosponsored by the University of Pittsburgh Press. 